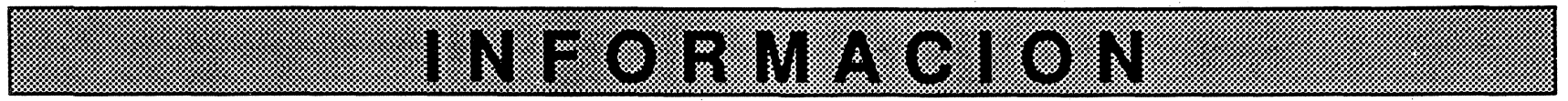

\title{
La manteca de karité
}

Por M. V. Ruiz Méndez y J. Huesa Lope

Instituto de la Grasa y sus Derivados. C.S.I.C.

Avda. P. García Tejero, 4. 41012 - Sevilla

\section{RESUMEN}

\begin{abstract}
La manteca de karité
Se hace una revisión bibliográfica sobre la extracción, composición, propiedades y aplicaciones de la manteca de karité.

PALABRAS-CLAVE: Aplicación - Composición química - Extracción - Información (articulo) - Manteca de Karité.
\end{abstract}

\section{SUMMARY}

\section{Shea butter}

A bibliographical review of the extraction, composition properties and applications of shea butter is made.

KEY-WORDS: Application - Chemical composition - Extraction - Information (paper) - Shea butter.

La manteca de karité es una grasa vegetal extraída de la semilla del Butyruspermum Parkii Kostchy, género Sapotácea. El árbol crece de forma espontánea sobre una zona muy extendida del Africa Central, a la que suele llamarse "Zona del Karité", (Sudán, Senegal, Gambia, Mali, Nigeria, Gabón, Togo, Alto Volta y Costa de Marfil) y recibe diversos nombres: Karité, Bambara, Shea, Malinké, etc, (1) (2).

La manteca de karité es una grasa muy apreciada por las poblaciones locales que la utilizan para su alimentación y cuidados del cuerpo. A su punto de fusión y a su elevado contenido en insaponificable (hasta un 17\%), la manteca de karité debe sus propiedades medicinales tradicionales (protección de la piel contra la intemperie y el sol, irritaciones superficiales, quemaduras, cortes, etc.), que justifican el interés actual en su comercialización.

La producción anual de la semilla se estima en 0,5 millones de toneladas, de las que la grasa extraída supone entre el 45 y el $60 \%$. El largo periodo de primera aparición de los frutos (12-15 años), así como de maduración del árbol (30 años), no contribuyen a que se extienda el cultivo de esta planta. (3) (4).
En este trabajo se resumen los conocimientos existentes sobre la extracción, composición y aplicaciones de la manteca de karité.

\section{Extracción de la grasa}

Los frutos del karité tienen el aspecto de una ciruela de 3 a $4 \mathrm{~cm}$ de diámetro, de color verde oscuro cuando están maduros. Se extrae de ellos una nuez o hueso, que contiene una almendra. La materia grasa representa alrededor del $50 \%$ del peso total de la almendra. (3).

La extracción se puede realizar mediante varios procedimientos, (4), aunque de manera general, se hace a partir de huesos liberados de la carne del fruto y puestos a secar al sol durante varios meses.

El procedimiento tradicional consiste en hacer hervir en agua los huesos previamente triturados; las materias grasas emergen y son recuperadas al enfriar (5). Con la aplicación de este proceso se obtiene, sin embargo, un bajo rendimiento en grasa.

Aunque la técnica tradicional permite obtener un producto de buen aspecto, el olor no es agradable $y$, sobre todo, el período de conservación es muy corto, ya que es inevitable, tras los lavados con agua caliente, el desarrollo de las reacciones oxidativas $y$, en consecuencia la aparición de la rancidez.

En la actualidad se prefiere un proceso de prensado de los huesos a temperatura controlada. El cocido previo de la almendra es absolutamente necesario y permite un mejor rendimiento en insaponificables. La manteca así obtenida es normalmente de color amarillo paja o amarillo verde, aunque ocasionalmente puede presentar colores rojizos. (5), (6).

\section{Composición de la manteca de karité}

Al igual que cualquier aceite o grasa vegetal, la manteca de karité está compuesta, en su mayor parte, por triglicéridos o ésteres del glicerol y ácidos grasos. 
Sin embargo, contiene una mayor proporción de la mezcla heterogénea de componentes menores que constituyen la fracción insaponificable. Este hecho es debido a que en la almendra se encuentran células especiales en las que se acumula el latex, el cual se mezcla con la grasa en el proceso de extracción. (2).

Existen muchas variedades de karité, que dan mantecas bastante diferentes, entre las cuales destaca la variedad Mangifolia por su aporte excepcional en materia insaponificable, (de 5 a 17\%). (1).

En las Tablas I y II se resumen las principales características físicas y químicas medias de la manteca de karité y la composición en ácidos grasos y glicéridos mayoritarios respectivamente, en la que destaca su elevado contenido en ácido esteárico.

Tabla I

Características físicas y químicas de la manteca de karité

Constantes fisicas:

$$
\begin{array}{lc}
\text { Peso especifco a } 15^{\circ} \mathrm{C}(\mathrm{g} / \mathrm{cc}): & 0.915-0.918 \\
\text { Rango de fusión }\left({ }^{\circ} \mathrm{C}\right): & 32-45 \\
\text { Indice de refracción: } & 1.463-1.467
\end{array}
$$

Indices químicos:

$$
\begin{array}{lc}
\text { Indice de saponificación(mgKOH/g) : } & 180-190 \\
\text { Indice de acidez (\%oleico): } & 2-9 \\
\text { Indice de yodo (nogIz/100g): } & 40-70
\end{array}
$$

Los valores de los índices físicos y químicos muestran una alta variabilidad, que se explica por la heterogeneidad del material, que crece de forma espontánea. En estudios realizados en aceites obtenidos de distintas almendras procedentes de la misma muestra y aplicando las mismas técnicas, se encuentran valores muy distintos de punto de fusión, color, acidez libre y contenido en grasa. (3).

La distribución de los ácidos grasos en los triglicéridos es coherente con la distribución clásica de las grasas vegetales, ya que sólo un $2-3 \%$ de ácido esteárico se encuentra esterificado en la posición central, que está ocupada por los ácidos oleico y linoléico. Se han llegado a identificar 21 tipos de triglicéridos, entre los cuales, los triglicéridos monoinsaturados representan el $50 \%$ de los totales y la fracción diinsaturada, aproximadamente el $25 \%$. Entre ellos, existen dos triglicéridos mayoritarios, 18:0 - 18:1 - 18:0 y 18:0 - 18:1 - 18:1 que constituyen aproximadamente el $60 \%$ de la manteca (7).

Tabla II

Composición de la manteca de karité. (1)

Composición media de los trigliceridos:

$\begin{array}{lr}\text { Diestearo-palmitina: } & 4.5 \% \\ \text { Oleo-diestearina: } & 34.4 \% \\ \text { Estearo-dioleina: } & 45.3 \% \\ \text { Palmito-dioleína: } & 11.3 \% \\ \text { Trioleinas y Iinoleinas: } & 4.5 \%\end{array}$

Composictón en ácidos grasos.

$\begin{array}{lc}\text { Mirístico: } & \text { inf } 0.5 \% \\ \text { Palmitico: } & 3-8 \% \\ \text { Esteárico: } & 30-40 \% \\ \text { Oleico: } & 41-50 \% \\ \text { Linoleico: } & 4-7 \% \\ \text { Aráquico: } & 0.2-1 \%\end{array}$

Lo más característico y valioso de la manteca de karité es la fracción insaponificable, más rica en principios activos, cuya proporción en la grasa es variable, dependiendo del origen geográfico del árbol y del grado de madurez de la fruta. Suele estar entre 3.5 y $17 \%$ en peso, mientras que la fracción insaponificable comúnmente encontrada en las grasas vegetales, suele oscilar entre 0.4 y $1 \%$ (8).

Los principales constituyentes de la fracción insaponificable son los alcoholes triterpénicos, hidrocarburos y esteroles. Entre los primeros, que constituyen entre el 65 y $70 \%$ del insaponificable, se han identificado como componentes mayoritarios el lupeol, brasseol, $\alpha$ y B-amyrina y parkeol. (8). Otros alcoholes identificados y característicos de esta grasa han sido 24-metilelanost-9 (11)-en-3B-ol (9), dammaradienol y 24-metilenedammarenol (10).

Respecto a los hidrocarburos, destaca una fuerte proporción de Kariteno, hidrocarburo sólido poliisoprénico, $\left(\mathrm{C}_{5} \mathrm{H}_{8}\right)_{n}$, cuyo grado de polimerización es del orden de 180. Es un cuerpo sólido cristalino cuyo punto de fusión es $63-64^{\circ} \mathrm{C}$ y viene a ser un $22 \%$ del insaponificable total. Se altera fácilmente por la temperatu- 
ra, el oxígeno atmosférico y la luz, dando lugar a otros compuestos oxigenados e hidrocarburos de distinto grado de polimerización (11).

Aunque en cantidades muy inferiores, la fracción esterólica presente en la manteca de karité, hace que esta grasa se distinga de otros aceites por su composición. Consta exclusivamente de $\Delta^{7}$-esteroles tales como, $\alpha$-spinasterol, $\Delta^{7}$-Stigmasterol, $\Delta^{7}$-avenasterol y 24-metilcolest-7-enol siendo los dos primeros los mayoritarios. Es de interés señalar que el patrón composicional de la manteca de karité es análogo al de los aceites vegetales de la familia Theaceae (8).

La manteca de karité, muy rica en hidrocarburos insaturados, es muy sensible a la oxidación, pues los tocoferoles naturales que contiene se encuentran en muy poca cantidad. Por ello, es necesario proteger la grasa con la adición de antioxidantes sintéticos.

Cuando el análisis de la fracción insaponificable se realiza después de saponificar la grasa, no es posible distinguir entre los alcoholes que se encuentran libres y esterificados. Un análisis más detallado de la manteca de Karité muestra que sólo una pequeña parte de los alcoholes presentes se encuentran libres, mientras que la mayoría -más del $85 \%$ - están presentes en la grasa en forma de ésteres de baja polaridad del ácido cinámico, en sus formas cis y trans, y de ácidos grasos.

No se ha observado selectividad en la esterificación de los alcoholes triterpénicos y esteroles, aunque la composición en ácidos grasos del saponificable no glicerídico es significativamente distinta a la de los glicéridos. El ácido cinámico, sin embargo, no ha sido encontrado libre ni esterificando al glicerol (12).

\section{Propiedades y utlilización de la manteca de karité}

Los usos de la manteca de karité derivan tanto de su composición glicerídica como de la especial composición cualitativa y cuantitativa de su fracción insaponificable.

Tradicionalmente, ha constituido una de las principales grasas de la dieta de los indigenas del Africa Central y su principal utilización fuera de su zona de producción ha sido en mezclas con manteca de cacao. Comercialmente es de gran interés, ya que la manteca de karité presenta unas características físicas muy similares a la manteca de cacao, cuyo precio es a menudo más elevado. Cuando la estearina de karité es incorporada a productos de chocolate, la estabilidad de éstos aumenta (12). Desde el punto de vista analítico, sin embargo, su detección es muy sencilla teniendo en cuenta las diferencias en la fracción insaponificable. Así, el análisis de la fracción hidrocarbonada o de los alcoholes triterpénicos permite asegurar, sin ninguna duda, la presencia de un $1 \%$ de manteca de karité en manteca de cacao (13) (14).

En su zona de producción, junto a su consumo como grasa comestible, se ha utilizado en aplicaciones medicinales en casos de eritemas solares, reumatismos, dermatitis, sequedad cutánea, etcétera.

Estas últimas aplicaciones, no relacionadas con el sector alimentario, son precisamente las que han promovido estudios dirigidos a conocer su composición y a desarrollar sus posibilidades en farmacología y cosmética (6) (15).

El principal interés para su aplicación en estos campos reside en su fracción insaponificable. Particularmente en cosmética, frente a la utilización de insaponificables aislados de aguacate y de soja, de muy elevado precio, el alto contenido de la manteca de Karité permite la utilización directa de la grasa en la formulación. Además, sus características físicas permiten su fácil aplicación y rápida absorción, contribuyendo igualmente a mejorar el aspecto de la piel (15).

Por otra parte, estudios realizados a nivel clínico, demuestran que la manteca de Karité no sólo es efectiva como protector de la piel ante la acción de agentes externos, sino que destaca entre sus propiedades más características una potente acción cicatrizante obteniéndose resultados más rápidos que los conseguidos hasta el momento con la utilización de pomadas corticoides grasas (16).

Desde el punto de vista de su composición, el principal interés está en su elevado contenido en ésteres del ácido cinámico que actúan como una eficaz pantalla de los rayos ultravioletas de longitud de onda 296-300 nm, que son los más activos en el desarrollo de eritemas solares.

Aunque las sintesis de la vitamina $D$, necesaria para el crecimiento está promovida por la radiación emitida en la misma zona del espectro ultravioleta, pequeñas dosis son tan efectivas para la síntesis como dosis masivas $y$, por ello, ante una exposición al sol, la eliminación de una parte sustancial de la radiación ultravioleta con un producto adecuado, no impide la formación de la vitamina y protege de las quemaduras (17).

En resumen, el interés de la manteca de Karité en el momento actual, está relacionado con sus aplicaciones en cosmética y farmacología donde, debido a las especiales características de su fracción insaponificable, adquiere un elevado valor añadido frente a las utilizaciones tradicionales y frente al resto de las grasas comestibles. 


\section{BIBLIOGRAFIA}

1. Mensier, P.-“Dictionnaire des huiles végétaux. Encyclopédie Biologique".- Tomo LII. Ed. Paul Lechevalier, París (1957) 108110.

2. Pansard, J.-"Contribution a l'étude du beurre de Karité".- Oléagineaux 4 (1950) 234-240

3. Kersahw, S. J. y. Hardwick, E.-"Heterogeneity within comercial contract analysis samples of Shea-nut kernels".- J. Am. Oil Chemists'Soc. 58 (1981) 706-710.

4. Bourlet, G.-“Le probléme du Karité."-Oléagineaux 6 (1950) 364367.

5. Lanzani, A., Bondioli, P, y col.-"Tecnologia integrale di estrazione della sostanza grassa e preparacione di farine dal seme di Karité".Riv. Ital. Sostanze Grasse 61 (1984) 375-383.

6. Proserpio, G., Perotti, G. y Cusmano, A.M.,-“Dal terzo mondo un nuovo lipide d'interesse cosmetico, il burro di Karité"-. Prodotto Chimico 16 (1975) $281-284$.

7. Sawadogo, K, y Bezard, J.-“Etude de la structure glycéridique du beurre de Karité".- Oléagineaux 37 (1982) 69-74.

8. Itoh, T., Tamura, T. y Matsumoto, T.-“Sterols and Methyl sterols in some tropical and subtropical vegetable oils."-. Oléagineaux 29 (1974) 253-258.

9. Itoh, T., Tamura, T. y Matsumoto, T.-"24-Metilenelanost-9 (11) -en-3B-ol. New triterpene alcohol from Shea Butter."- Lipids 10 (1975) 454-460.

10. Itoh, T., Tamura, T. y Matsumoto, T.-“24-Metilenedammarenol: a new triterpene alcohol from shea butter".- Lipids 10 (1975) 808-813.

11. Paquot, C. Argouds, S. y Querolle, M.-"Etudes sur l'insaponifiable du beurre de Karité. IV-Etude de la fractión latex".- Oléagineaux 7 (1952) 397-402.

12. Peers, K.E.-"The Non-glyceride Saponifiables of Shea Butter"--J. Sci. Food Agric. 28 (1977) 1000-1009.

13. Kanematsu, M.-"Studies on the hard butter. II. On the general properties of cacao butter".- Yukagaku 27 (1978) 354-356.

14. Derbesy, M., y Richert, T.-"Détection du beurre de karité dans le beurre de cacao".- Oléagineaux 34 (1979) 405-409.

15. Mital, H.C.--Shea butter. Cosmetic and drugs applications".- Drug Cosmetic Industry. 120 (1977) 30-33.

16. Tran, T.-"Le beurre de Karité: Propietés biologiques et Applications Cosmetiques".- Symposium "Les corps gras végétaux et animaux en cosmétologie." Ed. A.F.C.G. y S.C.F. (1984) 437 441.

17."Sun protectors". "Perfumes, Cosmetics and Soaps".- Vol III.- W.A. Pourcher, revisado por J. M. Howard.- 8. edición.-Ed. Chapman and Hall, Londres, 1978.

(Recibido: Junio 1990) 